\title{
MUSEOS Y DESARROLLO SOSTENIBLE. GESTIÓN MUSEÍSTICA Y COMUNICACIÓN DIGITAL PARA ALCANZAR LOS ODS
}

\section{MUSEUMS AND SUSTAINABLE DEVELOPMENT. MUSEUM MANAGEMENT AND DIGITAL COMMUNICATION TO ACHIEVE THE SDG}

Emma Gabriela Carbonell-Curralo': Universidad Complutense de Madrid. España. emmacarb@ucm.es

Mónica Viñarás Abad: Universidad Complutense de Madrid. España. mvinaras@ucm.es

\section{Cómo citar el artículo:}

Carbonell-Curralo, E. G. y Viñarás Abad, M. (2021). Museos y desarrollo sostenible. Gestión museística y comunicación digital para alcanzar los ODS. Revista de Ciencias de la Comunicación e Información, 26, 79-108. http://doi.org/10.35742/rcci.2021.26.e143

\section{RESUMEN}

Las instituciones museísticas han experimentado durante el siglo XX una evolución en su identidad y en sus prácticas que ha supuesto la cristalización de su misión educativa. De hecho, actualmente los museos tienen potestad para contribuir al logro del Desarrollo Sostenible, especialmente mediante su vinculación con el ODS 4 (Educación de calidad). Por ello, este trabajo tiene como área temática la comunicación de las instituciones museísticas. Se justifica en aspectos tanto metodológicos como coyunturales al inscribirse en un contexto nacional que ha ensalzado la misión del plan de acción aprobado por las Naciones Unidas y que ha impulsado nuevos mecanismos para alcanzar los ODS. Teniendo en cuenta que los museos, independientemente de su titularidad, son actores que contribuyen al valor público produciendo capital social y cultural, el presente trabajo tiene como objeto de estudio conocer el lugar que ocupan los museos españoles en la Agenda 2030. Se aporta un enfoque histórico y una consulta cualitativa a los profesionales de las instituciones museísticas a fin de ofrecer resultados con los que transmitir la necesidad de incorporar la Agenda 2030 en los planes estratégicos de los museos para aumentar la difusión de la misma y generar el máximo valor educativo para la ciudadanía.

Palabras clave: Agenda 2030, Comunicación, Educación, Museo, ODS 4.

\footnotetext{
${ }^{1}$ Emma Gabriela Carbonell-Curralo: Universidad Complutense de Madrid (emmacarb@ucm.es) Periodista especializada en Comunicación de las Organizaciones.
} 


\section{ABSTRACT}

During the 20th century museums have experienced an evolution in their identity and practices, which has brought the realization of their educational mission. Under the present context of the Agenda 2030, this research aims to expose how museums are cultural actors with the power to contribute into achieving Sustainable Development, especially through their connection with the SDG 4 (Quality Education). For this reason, the thematic area of this work is the communication of museum institutions and it is justified in both methodological and circumstantial aspects as it is part of a national context, in which the mission of the action plan approved by the United Nations has been extolled and new mechanisms have been promoted to achieve the SDGs. Bearing in mind that museums, regardless of their ownership, are actors that contribute to public value by producing social and cultural capital, the purpose of this paper is to study the place of Spanish museums in the 2030 Agenda. It provides a historical approach and a qualitative consultation with museum professionals in order to offer results with which to convey the need to incorporate the 2030 Agenda in the strategic plans of museums to increase its dissemination and generate the maximum educational value for citizens.

Keywords: Agenda 2030, Communication, Education, Museum, SDG 4.

\section{INTRODUCCIÓN}

En un contexto global donde el Desarrollo Sostenible supone una revolución en la gestión de las instituciones, los museos se revelan como agentes sociales esenciales para la consecución de la Agenda 2030. Especialmente a través del Objetivo de Desarrollo Sostenible número 4 (Educación de Calidad). Por ello, resulta de interés investigar si la comunicación museística, y concretamente su dimensión digital, se identifica como un recurso para la difusión de esta labor. Así pues, desde un punto de vista social y bajo una perspectiva nacional, se estudia si las organizaciones museísticas asumen públicamente su papel en la obtención del Desarrollo Sostenible. Para tal fin, el presente trabajo tiene como objeto de estudio conocer el lugar que ocupan los museos españoles en la Agenda 2030 a través de la opinión de sus profesionales.

\section{OBJETIVOS}

El objetivo principal de esta investigación es conocer la función que desempeña la comunicación digital en la gestión museística para la consecución de los ODS. Además, para alcanzar dicho objetivo, se han planteado una serie de objetivos previos de carácter secundario como: percibir la relación entre los museos españoles y la Agenda 2030, con especial interés en el ODS 4 (Educación de Calidad); averiguar el nivel de conocimiento que las instituciones museísticas nacionales tienen de la Agenda 2030 mediante una consulta a sus profesionales; y conocer la relevancia de la comunicación institucional museística en la difusión y consecución de los ODS. 


\section{METODOLOGÍA}

Para alcanzar dichos objetivos se ha diseñado una investigación descriptivaexploratoria que se apoya en dos técnicas. En primer lugar, se ofrece un compendio de fuentes secundarias para elaborar un estado de la cuestión que recoja las teorías sobre comunicación corporativa y Relaciones Públicas en las instituciones museísticas. Asimismo, se presenta información relativa a la Agenda 2030 a partir de las instituciones y organismos públicos pertinentes.

En segundo lugar, se expone una recopilación de datos primarios al haber recogido información de la realidad "directamente por quien realiza la investigación" (Berganza y Ruíz, 2005, p.78). El procedimiento para la obtención de dicha información ha sido la entrevista estructurada de respuestas abiertas al proporcionar a todos los destinatarios un listado de preguntas en la misma sucesión y con la misma formulación.

Las preguntas se han elaborado a partir de las variables del estudio: la percepción de los profesionales de los museos sobre la Agenda 2030/ODS en la gestión de la institución y su opinión sobre la aportación de la comunicación en este sentido. Por ello, la batería de preguntas ha tenido como destinatario a las instituciones museísticas del territorio nacional registradas en el Directorio de Museos y Colecciones de España, "una herramienta que permite conocer y acercase a los más de 1.500 museos y colecciones museográficas existentes en España, siendo una viva representación del rico panorama museístico actual" (Ministerio de Cultura y Deporte, s.f.). Se ha procedido a enviar el listado de preguntas a cada uno de los museos del territorio nacional, independientemente de su tamaño, temática, titularidad o gestión. El universo a estudiar ha estado formado por el conjunto de los 1.161 museos registrados en el Directorio de Museos y Colecciones de España: 165 museos de Andalucía, 60 museos de Aragón, 62 museos de Canarias, 10 museos de Cantabria, 147 museos de Castilla y León, 96 museos de Castilla-La Mancha, 114 museos de Cataluña, 3 museos de la ciudad de Ceuta, 3 museos de la ciudad de Melilla, 100 museos de la Comunidad de Madrid, 7 museos de la Comunidad Foral de Navarra, 135 museos de la Comunidad Valenciana, 30 museos de Extremadura, 66 museos de Galicia, 37 museos de Islas Baleares, 11 museos de La Rioja, 62 museos del País Vasco, 20 museos del Principado de Asturias y 33 museos de la Región de Murcia.

El entrevistado ha podido responder con sus propias palabras y en la extensión deseada. Por lo que las entrevistas han aportado una perspectiva cualitativa al permitir estudiar los "significados compartidos intersubjetivamente expresados en el lenguaje" (Berganza y Ruíz, 2005, p.31). De esta manera, para analizar las respuestas proporcionadas se ha seguido una metodología interpretativa.

La ejecución de las preguntas se ha realizado mediante vía telemática, tanto por tratarse de una muestra de carácter disperso como por considerarse que mediante este sistema el entrevistado podría ejercer una mayor reflexión a la hora de remitir sus respuestas. Cabe mencionar que en el cuerpo previo del mensaje se han formulado los objetivos de estudio, así como la garantía de confidencialidad y anonimato del participante que así lo solicitase. Se ha favorecido que el destinatario de las preguntas en las instituciones museísticas fuese, bien el área de comunicación, bien la dirección 
de la institución. Sin embargo, en algunas ocasiones, por la naturaleza del museo, se ha contactado con la institución mediante una dirección de correo electrónico de carácter general para que mediante gestión interna se estimase quién podría ser la persona más apropiada para el desarrollo de las respuestas.

Las preguntas planteadas han sido las siguientes:

1. ¿Conoce la Agenda 2030 y los ODS?

2. ¿Hasta qué punto cree que la cultura es un factor relevante para lograr un desarrollo sostenible?

3. ¿Cree que los museos están trabajando actualmente en esta línea? ¿De qué manera?

4. ¿Considera que la comunicación de los museos va orientada a dar a conocer su papel en el Desarrollo Sostenible?

5. ¿Piensa que los museos utilizan todos los recursos posibles de la comunicación digital para contribuir al Desarrollo Sostenible?

En el apartado de Anexo puede localizarse la tabla (Ver Tabla $1^{2}$ ) donde figura la muestra de las instituciones museísticas nacionales que han colaborado con el estudio. El orden en el que se presentan estos datos es de tipo alfabético en base a: primero, la comunidad autónoma en la que se encuentra la institución museística; segundo, la provincia en la que se encuentra la institución museística; y tercero, el nombre de la propia institución museística. Asimismo, podrá observarse una recopilación sintética de los datos obtenidos (Ver Tablas $2^{3}$ y $3^{4}$ ).

\section{DISCUSIÓN}

\subsection{Comunicación desde el modelo museográfico tradicional al socio-digital}

"De cerrado a abierto, de para unos pocos a para cuantos más mejor, de elitista a populista, de callado a parlanchín" (Mateos, 2012, p.11).

En el siglo $X X$ los museos se convirtieron en instituciones públicas de vocación universal. Este factor, unido al surgimiento de una cosmovisión basada en el fin de los metarrelatos, permitió desarrollar nuevos modelos museográficos caracterizados por su naturaleza didáctica. El Museo Tradicional fue sustituido por el Museo Social, configurado a partir de principios patrimoniales (materiales e inmateriales) de renovación y de interactuación entre el territorio, la población y la colección. De esta forma, se logra descodificar el patrimonio para facilitar su comprensión a toda la sociedad, se potencia la dimensión interpretativa del museo y se configura una visión museológica basada en la multiculturalidad y amparada en principios inclusivos ante la diversidad material, corporal o simbólica (Hernández, 2018). La dimensión comunicativa y educativa del museo no siempre ha tenido como objeto interaccionar con su público. Pero desde que la museología superase el interés por los objetos para alcanzar otros espacios más allá de los abarcados por el coleccionismo y la conservación, no solo pudo lograrse un cambio conceptual y metodológico del término, sino que las instituciones museísticas mejoraron sus estrategias para

\footnotetext{
2 Tabla 1. Museos que han formado parte del estudio.

3 Tabla 2. Resumen de respuestas de los museos del territorio nacional.

4 Tabla 3. Museos participantes del territorio nacional que desconocen la Agenda 2030 y los ODS.
} 
relacionarse con el público y difundir a la ciudadanía conocimientos de carácter patrimonial con fines didácticos y educativos. Más adelante, con la incorporación de tecnologías en la museografía, se origina la noción de Museo Social Digital. Las TIC 5 permiten que la comunicación y el diálogo con el museo ya no solo se produzcan dentro del espacio físico de este (Moreno, 2005), mientras que las TAC 6 facultan el aprendizaje, el acceso al patrimonio y el desarrollo de la educación museística en cualquier lugar del mundo gracias al espacio virtual (Rivero, 2010). Análogamente, la comunicación museística adquiere un fin lúdico y deleitoso ya que el consumidor cultural se inscribe en un contexto de hiperconectividad y globalización donde el museo ya no considera al público un elemento constituyente del proceso museográfico sino el objetivo de su actividad.

Tabla 4. Comparación evolutiva de los arquetipos museísticos

\begin{tabular}{lll}
\hline \multicolumn{1}{c}{ Museo Tradicional } & \multicolumn{1}{c}{ Museo Social } & \multicolumn{1}{c}{ Museo Social Digital } \\
\hline Espacio para algunas personas. & $\begin{array}{l}\text { Espacio para todas las } \\
\text { personas. }\end{array}$ & $\begin{array}{l}\text { Espacio para todas las } \\
\text { personas. }\end{array}$ \\
\hline El docente transmite. & El docente media. & El docente dinamiza. \\
\hline El público es un receptor. & $\begin{array}{l}\text { El público es un constructor de } \\
\text { conocimiento. }\end{array}$ & $\begin{array}{l}\text { El público es un consumidor de } \\
\text { experiencias. }\end{array}$ \\
\hline El aprendizaje es determinista. & $\begin{array}{l}\text { El aprendizaje es } \\
\text { constructivista. }\end{array}$ & El aprendizaje es personalizado. \\
\hline La comunicación es & La comunicación es & La comunicación es \\
unidireccional. & bidireccional. & multidireccional. \\
\hline
\end{tabular}

Fuente: Elaboración propia a partir de Llerena (2015) y Mas Iglesias (2018).

\subsection{Agenda 2030 y ods 4 para configurar la rsc de las instituciones museísticas}

La labor comunicativa de las instituciones museísticas se enmarca dentro del conjunto de actuaciones que conforman las Relaciones Públicas. De este modo, se logra la producción de intangibles con los que generar una identidad de la institución (Viñarás, 2016), y se alcanza el entendimiento mutuo con el público (Viñarás, 2005) gracias al carácter gerencial de las Relaciones Publicas que, aunque persuasivas, son ajenas "a los objetivos comerciales y económicos del marketing, con el que a veces equivocadamente se confunden" (García-Nieto, Viñarás-Abad y Cabezuelo-Lorenzo, 2020, p.9).

En el tiempo actual, se impone el uso de "técnicas de comunicación, negociación y establecimiento de relaciones hábiles y probadas en el tiempo" (Johnston, 2018, p.25) para que el museo configure su engagement, alcance nuevos públicos, manifieste los servicios y labores que le ocupan, proyecte una imagen que transmita su identidad corporativa y favorezca su reputación. Cabe decir que los museos necesitan una licencia social para operar, ya que la $\mathrm{RSC}^{7}$ de una institución responde a las expectativas y a la visión que la sociedad tiene sobre lo que significa ser una organización socialmente responsable en un momento concreto (Hurst e Ihlen, 2018, pp.135-138).

\footnotetext{
${ }^{5}$ TIC (Tecnologías de la información y la comunicación).

${ }^{6}$ TAC (Tecnologías para el aprendizaje continuo).

${ }^{7}$ RSC (Responsabilidad Social Corporativa).
} 
Dependiendo de si se ejecuta un análisis basado en la imagen pública de la institución museística o si se emprende un estudio basado en manifiestos de organismos internacionales, como el ICOM o la UNESCO, la función educativa de los museos puede percibirse bajo perspectivas complementarias. Por un lado, como parte de su naturaleza y su cometido, si se tiene en cuenta tanto la definición oficial de museo como la evolución del rol social asumido por la institución. Por otro, como parte de su estrategia, si favorece la generación de intangibles que desarrollen una imagen institucional positiva y un comportamiento corporativo que satisfaga a sus stakeholders. En cualquier caso, los museos tienen una función sustancial a la hora de impulsar el plano educativo de la Agenda 2030, lo que contribuye a la consecución del ODS 4 en particular y de los ODS en general, al relacionarse la educación con los demás objetivos.

La dimensión cultural del desarrollo y el plano educativo de la Agenda 2030 se manifiesta en la meta 4.7. Así que, teniendo en cuenta que los museos son lugares "donde se plasma perfectamente el vínculo entre cultura y desarrollo sostenible" (UNESCO, 2015, p.24), se asume que las instituciones museísticas son actores capaces de acelerar la implementación del Desarrollo Sostenible al impulsar la cultura como un elemento transformador. La Agenda 2030 necesita a los museos, no solo por sus funciones, sus capacidades y su potencial, sino porque solo mediante la cooperación de todos los actores sociales podrá alcanzarse el Desarrollo Sostenible.

\begin{tabular}{|c|c|c|c|}
\hline Objetivo1 & La educación es crucial para salir de la pobreza. & Objetivo 10 & $\begin{array}{l}\text { La igualdad de oportunidades en el acceso a la educación ha demostrado su eficacia contra la } \\
\text { desigualdad social y económica. }\end{array}$ \\
\hline Objetivo 2 & $\begin{array}{l}\text { La educación es fundamental para avanzar hacia unos métodos agrícolas más sostenibles y } \\
\text { adquirir conocimientos sobre nutrición. }\end{array}$ & Objetivo 11 & $\begin{array}{l}\text { La educación puede aportar las competencias necesarias para contribuir a configurar y } \\
\text { mantener unas ciudades más sostenibles y alcanzar la resiliencia en situaciones de desastre. }\end{array}$ \\
\hline Objetivo 3 & $\begin{array}{l}\text { La educación puede aportar una contribución decisiva para muchas cuestiones relativas a la } \\
\text { salud, como la mortalidad prematura, la salud reproductiva, la difusión de las enfermedades, el } \\
\text { bienestar y los estilos de vida saludables. }\end{array}$ & Objetivo 12 & $\begin{array}{l}\text { La educación puede influir decisivamente en los patrones de producción (p. ej., respecto a la } \\
\text { economía circular) y en la información de los consumidores sobre la producción de bienes más } \\
\text { sostenibles y la limitación de los desechos. }\end{array}$ \\
\hline Objetivo 5 & $\begin{array}{l}\text { La educación de las mujeres y las niñas es particularmente importante para lograr la } \\
\text { alfabetización básica, desarrollar las competencias y capacidades participativas y mejorar las } \\
\text { oportunidades vitales. }\end{array}$ & Objetivo 13 & $\begin{array}{l}\text { La educación es clave para la comprensión de los efectos del cambio climático por el público } \\
\text { en general, así como para la adaptación y la mitigación, especialmente en el plano local. }\end{array}$ \\
\hline Objetivo 6 & $\begin{array}{l}\text { La educación y la formación aumentan las competencias y la capacidad para usar los recursos } \\
\text { naturales de forma más sostenible y pueden contribuir a promover la higiene. }\end{array}$ & Objetivo 14 & $\begin{array}{l}\text { La educación es importante para concienciar sobre el entorno marino y fomentar un consenso } \\
\text { proactivo respecto a su uso racional y sostenible. }\end{array}$ \\
\hline Objetivo 7 & $\begin{array}{l}\text { Los programas educativos, especialmente los no formales y los informales, pueden promover } \\
\text { una mejora en la conservación de la energía y el uso de fuentes de energía renovables. }\end{array}$ & Objetivo 15 & $\begin{array}{l}\text { La educación y la formación desarrollan las competencias y la capacidad para garantizar } \\
\text { medios de subsistencia sostenibles y conservar los recursos naturales y la biodiversidad, } \\
\text { especialmente en entornos amenazados. }\end{array}$ \\
\hline Objetivo 8 & $\begin{array}{l}\text { Hay una relación directa entre la vitalidad económica, la iniciativa empresarial, las } \\
\text { competencias para el mercado laboral y el nivel educativo. }\end{array}$ & Objetivo 16 & $\begin{array}{l}\text { El aprendizaje social es vital para propiciar y promover unas sociedades participativas, } \\
\text { inclusivas y justas, así como la coherencia social. }\end{array}$ \\
\hline Objetivog & $\begin{array}{l}\text { La educación es necesaria para desarrollar las competencias que permiten construir unas } \\
\text { infraestructuras más resilientes y lograr una industrialización más sostenible. }\end{array}$ & Objetivo 17 & $\begin{array}{l}\text { Elaprendizaje permanente desarrolla la capacidad para entender y promover las políticas y } \\
\text { prácticas de desarrollo sostenible. }\end{array}$ \\
\hline
\end{tabular}

Figura 1. Relación de la educación con los demás Objetivos de Desarrollo Sostenible.

Fuente: UNESCO (2017).

Declara McGhie (2019) que los museos necesitan a los ODS. Primero, porque logra que los museos generen impacto al dirigir "sus actividades a una agenda externa, del mundo real, en apoyo del bienestar local y global" (p.35). Y segundo, porque les aporta "objetivos para que las partes interesadas trabajen juntas" (p.35). Igualmente, el ICOM (2020a) reafirma la necesidad de los ODS no solo porque permitan a los museos conectar con otros sectores y poner sus múltiples recursos a disposición de una buena causa, sino porque los ODS "les ofrecen una agenda global ambiciosa que les puede ayudar a demostrar su relevancia y su impacto". 
Por ello, teniendo en cuenta la conexión entre el museo y las necesidades advertidas en el plan de acción de la Agenda 2030, se manifiesta el que debiera ser el cometido de los museos en el contexto actual por ser actores sociales y culturales profundamente ligados a algunas de las aspiraciones desarrolladas en los ODS. Principalmente a las vinculadas con la generación de oportunidades de aprendizaje, ya sea a través de los diálogos museográficos establecidos en el museo, la promoción de las TAC o el desarrollo de prácticas educativas del ámbito formal, del no formal, del informal o del aprendizaje a lo largo de toda la vida (lifelong learning).

\subsection{La dimensión digital museística para la reformulación museológica y museográfica}

La realidad museística caracterizada tanto por el ejercicio de la cibermuseografía en el Museo Social Digital, como por la generación de procesos comunicativos que logran constituir engagement para con sus stakeholders, puede ejemplificarse a través de la coyuntura surgida a partir del brote de COVID-19 al haberse desarrollado una tarea comunicativa, educativa y ociosa donde la actividad online se ha vuelto una de las herramientas más fuertes de las instituciones museísticas. De esta forma, sumado al escenario de la Agenda 2030, la COVID-19 ha supuesto un cambio de paradigma tanto en la noción de museo como en las expectativas dirigidas hacia el ICOM. Por lo que el Consejo presentó en diciembre de 2020 (ICOM 2020b) una nueva y ambiciosa metodología con la que delimitar una renovada acepción de museo que logre describir tanto su coyuntura actual como su declaración de intenciones.

Con todo, respecto al empleo de la tecnología, en el webinar Nuevos retos para la cultura y el turismo. Museos y ciudades ante la revolución digital de la era post-covid (CM Málaga, 2020) Teresa Reyes Bellmunt, presidenta de ICOM España, declaraba que "no se ha producido todavía la verdadera revolución digital [...], sino que más bien ha sido una evolución digital" porque la mayoría de los museos nacieron antes de la era digital "y ahora, básicamente se está trabajando en digital con concepción analógica". Además, en referencia a esta realidad digitalizada vale la pena señalar que "la mitad de la humanidad no tiene acceso a las tecnologías digitales" (UNESCO, 2020) con lo que la brecha tecnológica deja a una parte de la población desasistida y al margen de la conversación universal de 2020.

\subsection{Las entrevistas estructuradas de respuesta abierta}

En base al contexto descrito, y a fin de elaborar una investigación descriptiva y analítica sobre los objetivos expuestos, proceden a presentarse las respuestas facilitadas por las instituciones museísticas del territorio nacional registradas en el Directorio de Museos y Colecciones de España. De los listados de preguntas emitidos, un total de 114 museos del territorio nacional han aportado sus respuestas al estudio sobre Museos y Desarrollo Sostenible. Es decir, casi el 10 por ciento del total de los museos del territorio español. La procedencia de las respuestas se distribuye entre el personal directivo (59 personas), la plantilla de comunicación (20 personas) y otras secciones del museo (35 personas). A continuación se expone la información facilitada por los profesionales de las organizaciones museísticas durante las entrevistas, lo que permite generar una discusión en torno al objeto de estudio. 


\subsubsection{El conocimiento de los museos sobre la agenda 2030 y los ods}

De las 114 respuestas obtenidas, 28 museos afirman no conocer la Agenda 2030, ni Ios ODS, ya sea de una forma amplia o somera. De estos, 8 son museos de titularidad privada y 20 de titularidad pública, estando 17 adscritos a la Administración Local, 1 a la Administración de las Comunidades Autónomas y 2 a la Administración General del Estado (Ver Tabla 3). Aun así, no todas las respuestas afirmativas representan un conocimiento homogéneo de los ODS y la Agenda 2030 ya que algunas instituciones declaran conocer estos elementos "en líneas generales", "de forma superficial", "poco", "vagamente", "no de forma detallada" o "no en profundidad". También se ha registrado que algunos museos afirman conocer los ODS pero no la Agenda 2030. E Incluso, se han obtenido respuestas que afirmaban conocer los Objetivos de Desarrollo Sostenible pero no su acrónimo de ODS.

Por otra parte, entre las maneras en las que los museos afirman haber conocido la Agenda 2030 y los ODS puede destacarse los medios de comunicación, las publicaciones especializadas o las actividades formativas como las organizadas por la Asociación Ibero-Macaronésica de Jardines Botánicos o las I Jornadas sobre Cultura y Desarrollo Sostenible organizadas por la Red Española para el Desarrollo Sostenible. Entre los museos que sostienen conocer los ODS y la Agenda 2030 puede destacarse la declaración del Museo Nacional de Antropología que afirma estar familiarizado con la Agenda 2030 y con los Objetivos de Desarrollo Sostenible al ser una "institución pública estatal", la del Museo Picasso Málaga que espera que se alcancen estos objetivos "en especial para aumentar la calidad de la educación" o la del Museo de Gavà, que afirma conocer su existencia pero no trabajar teniendo en cuenta sus contenidos.

Teniendo en cuenta que para que la Agenda 2030 genere valor público se precisa de "un contexto multisectorial y multinivel, que va más allá del gobierno" (Canel, 2018, p.85), la relevancia de que las instituciones museísticas integren en su planificación estratégica el Desarrollo Sostenible y se comprometan con él puede generar alianzas colaborativas favorables con la Administración, así como contribuir a fortalecer los vínculos con su público, a conectar con sus partes interesadas o a desencadenar una repercusión social, cultural, económica y medioambiental positiva.

El hecho de que todavía haya museos que manifiesten desconocer por completo la Agenda 2030 y los ODS refleja un trabajo pendiente por parte de instituciones como el ICOM. Ahora bien, si del conjunto de instituciones museísticas las de carácter público desconocen estos principios, se revela que, a pesar de los avances realizados, es necesario mejorar los esfuerzos por parte de la Administración. No ha de subestimarse la colaboración que los museos pueden aportar a las medidas con las que el gobierno pretende impulsar los ODS. En 2019 el Ministerio de Asuntos Exteriores, Unión Europea y Cooperación reconocía la relación que existe entre cultura y desarrollo humano, pero los museos son actores culturales que participan en el logro del Desarrollo Sostenible, y la Administración debe servirse de todo su potencial.

La incorporación de los ODS en las instituciones no solo ha de tenerse en cuenta por cuestiones éticas, sino porque la organización podría disfrutar de ventajas 
competitivas que implicarían el acceso a activos tangibles, como las recompensas económicas, mediante activos intangibles (Canel y Luoma-aho, 2017, p.39). Por ejemplo, los museos no solo reducirían costes derivados del ahorro energético, sino que captarían a aquel visitante que apoya a instituciones comprometidas con la sostenibilidad. Por su parte, la asimilación del Desarrollo Sostenible en el sector público tiene por fin tanto servir como un espejo donde la ciudadanía y las empresas puedan mirarse, como la recepción de un beneficio a largo plazo para los ciudadanos y para sus stakelholders como son, concretamente, los museos.

\subsubsection{El cometido de la cultura y la educación en el museo}

Las personas entrevistadas reconocen que la cultura es fundamental para asimilar la educación como forma de alcanzar el desarrollo social. Por lo tanto, el papel de los museos en la consecución de los ODS resulta imprescindible aunque se necesiten más recursos para alcanzar todo su potencial. En otras palabras, "se puede considerar la cultura como un motor que ayuda a lograr el Desarrollo Sostenible" (Museo Sefardí) ya que esta "participa de una forma activa en la educación, en la concienciación y en la difusión de los ODS a toda la sociedad" (Museo de la Santa Cruz).

Bajo la perspectiva del Desarrollo Sostenible, la cultura no solo se identifica con el progreso o el crecimiento económico, sino con una óptica en clave humana. Es decir, "lo que, desde una visión integral del ser humano, supone y significa tener en cuenta todas las dimensiones de la persona" (Museo del Retablo). En este sentido, el Museo Etnográfico de Talavera de la Reina indica que "la cultura de un país juega un papel determinante en el desarrollo de los seres humanos", ya sea a nivel conductual, social o económico, puesto que estos factores influyen a la hora de que "las personas alcancen un nivel de vida próspero". De esta manera, se opina desde el Museo del Cine de Madrid lo imprescindible que resulta no apelar a la cultura "de forma subjetiva, impregnándola de intereses políticos o económicos".

Respecto al vínculo entre la cultura y el Desarrollo Sostenible, el Museo Valenciano de Etnología desarrolla que el hecho de que la cultura no tenga un epígrafe propio en los ODS denota la poca importancia que se le da al sector cultural a pesar de que tenga un "papel fundamental tanto en la divulgación de los valores de los ODS como en la aplicación de los mismos en el propio desarrollo de la actividad cultural". La cultura es pues, un elemento central de las políticas de desarrollo como único medio para alcanzar una gestión inclusiva y equitativa. No hay desarrollo sostenible sin factores culturales y, por tanto, el museo apela a la conciencia ciudadana. Para aportar soluciones que aboguen por la inclusión y la erradicación de la desigualdad.

La cultura no es solo un instrumento para "tomar conciencia de realidades que sentimos, vivimos, experimentamos" (Museo de Navarra), sino que "es una herramienta didáctica" (Museo Municipal de la Cuchillería) que actúa como facilitador para alcanzar bien la tradicional noción de desarrollo social, bien el actual objetivo de Desarrollo Sostenible (Museo de las Ciencias de Valencia). Un pilar fundamental que impulsa las acciones individuales y colectivas, por lo que es más importante ajustar la cultura con los ODS que priorizar únicamente sobre cuestiones de distinta materia estratégica (Museo de la Universidad de Navarra). 
El Desarrollo Sostenible se ha definido durante muchos años en base a variables medioambientales, económicas y sociales. Pero sin la dimensión cultural no es posible lograr un desarrollo sostenible completo. La cultura no es un lujo. No podemos transformar nuestro marco de vida y convivencia a nivel internacional sin tener en cuenta la cultura o las culturas que están incidiendo enormemente en nuestros problemas globales. La cultura es el instrumento más potente para difundir y canalizar el mensaje de la sostenibilidad (Museo Nacional de Artes Decorativas).

Las respuestas aportadas por los entrevistados manifiestan cómo no se interioriza que la cultura sea el camino para alcanzar el Desarrollo Sostenible. Así, se impone la necesidad de dar a conocer mejor cuáles son los ODS, difundir de qué manera y con qué acciones la cultura puede desempeñar "el papel relevante que le toca" (Museo de Ciencias Naturales de Barcelona) y "contribuir a conseguir un cambio de mentalidad en las instituciones, las empresas y los ciudadanos" mediante una "labor de integración de la necesidad de la sostenibilidad" (Museo ICO). De acuerdo con lo expresado, el Museo Nacional Centro de Arte Reina Sofía formula que la dimensión cultural del Desarrollo Sostenible no es lo bastante reconocida, por lo que su "presencia en los informes y las declaraciones es limitada". Además, la institución añade:

No está suficientemente aprovechado el potencial de la participación ciudadana en la vida cultural y las colaboraciones culturales a nivel local, nacional e internacional [...] Las referencias a la cultura en los ODS son escasas y no reconocen suficientemente las muchas maneras en que los aspectos culturales influyen y contribuyen al Desarrollo Sostenible.

Si la cultura favorece la difusión, sensibilización y la educación de las personas, por ende también fomenta la obtención del Desarrollo Sostenible. Con que "cultura y educación son, no relevantes, sino fundamentales para lograr el Desarrollo Sostenible. Son "la mejor manera de concienciar a la población" (Museo Etnográfico Extremeño González Santana), de pautar "la forma de desarrollar nuestras ciudades y nuestro territorio" y de reconocer la historia "de otros pueblos que están en peligro por el desarrollo no sostenible que se ha llevado a cabo hasta ahora" (Museo Íbero).

Pero el simple hecho de hacer público el binomio cultura-educación no garantiza el logro de la Agenda 2030 ya que son factores "insuficientes si no van acompañadas de medidas firmes de los gobiernos" (Museo Pedagógico del Niño), de una gestión sostenible por parte de las instituciones (Museo Cerralbo) o de otros agentes como "directrices de las autoridades, presupuestos, etc." (Museo Diocesano de Tarragona).

La cultura y la educación son los pilares básicos en los que ha de asentarse cualquier proyecto de mejora para la vida de los ciudadanos de un país. En el entendimiento de que solo el convencimiento y la formación pueden lograr que de forma voluntaria todos contribuyamos a la consecución de un mundo mejor, para todos sus habitantes y para todo lo que existe en nuestro planeta (Museo de Aeronáutica y Astrofísica). 


\subsubsection{Los museos como aceleradores del desarrollo sostenible}

Mayoritariamente los entrevistados han manifestado la responsabilidad que los museos tienen como agentes catalizadores del desarrollo, especialmente en las comunidades donde se ubican. Si el mundo actual demanda un desarrollo más consciente y sostenible, los museos pueden y deben contribuir a su consecución. De hecho, las exposiciones y programas educativos ponen de manifiesto, cada vez en mayor medida, los valores que deben servir de modelo a la sociedad que aspiramos ser (Museo Guggenheim Bilbao).

El Desarrollo Sostenible es un objetivo global y primordial (Museo del Calzado), con lo que las organizaciones dedicadas a la divulgación cultural también han de transmitir valores vinculados con los ODS (Ekainberri). Por eso, "todas las actividades que directa o indirectamente están vinculadas a los museos han de tener en cuenta el Desarrollo Sostenible" (Fundación Apel les Fenosa). En esta línea, afirma el Museo Nacional de Antropología que las instituciones museísticas son interlocutores que trasmiten valores imprescindibles como, por ejemplo, la sostenibilidad. Por eso, donde haya un museo podrá experimentarse un cambio en el "entorno social, tanto en la economía, en la educación de sus gentes o en las conductas sociales de sus habitantes" (Museo Fundación Pecharromán).

En relación a esto, el TOPIC manifiesta que las instituciones museísticas no deben ser entidades al margen del mundo: con piezas de gran valor pero poca relación con la sociedad. Los museos ya no pueden ser fósiles del pasado, sino actores que dialoguen con el presente porque, en nuestros días, el museo "tiene la firme vocación de ser un espacio vivo inserto en la comunidad en la que se ubica" (Museo Nacional de Arte Romano) al haberse adaptado a la sociedad y "a las circunstancias de cada momento de la historia" (Museo Sefardí). Por todo ello, la obtención del Desarrollo Sostenible "es un objetivo y una razón de ser de este tipo de instituciones en el siglo XXI" (Museo Picasso Málaga). La responsabilidad que los museos tienen sobre el Desarrollo Sostenible es "la que debe tener cualquier institución al servicio de la sociedad que la sustenta" (Museo del Pueblo Gallego). Por ello, los museos tienden a ser cada vez más sensibles a evidenciar y revindicar su papel en los cambios de modelo de sociedad (Museo Guggenheim Bilbao).

Sin embargo, y a pesar de lo expuesto, varios de los profesionales consultados han esclarecido cómo influye la notoriedad de la institución a la hora de abordar estrategias de sostenibilidad dado que "no hay una línea de trabajo compartida entre todos los museos para abordar los ODS" (Museo de la Valltorta). Así, entre las observaciones realizadas por las instituciones museísticas, se haya la necesidad de emprender iniciativas sostenibles más contundentes 0 , al menos, unas directrices comunes de trabajo (Museo del Azafrán). En esta línea, el Museo Frederic Marès no considera que el ejercicio de la mayoría de los museos fomente el Desarrollo Sostenible, menos aún en "los más pequeños y aquellos que dependen de organismos y fondos públicos, pues no disponen de los recursos necesarios".

Los que trabajamos en museos de dimensiones medianas y pequeñas tenemos por delante muchos retos que tienen que ver con la pura supervivencia de nuestras instituciones. Otra cosa son los grandes museos, que, teniendo 
supuestamente cubiertas sus necesidades, pueden apostar por acciones como las descritas (Museo Diocesano de Tarragona).

A partir de las respuestas obtenidas se percibe que, a pesar de lo deseado, la Agenda 2030 no se articula en los museos españoles de manera homogénea puesto que las instituciones están condicionadas "por su carácter público o privado, por su modalidad de gestión, su acceso a presupuesto propio y su capacidad jurídica de obrar" (Museo Cerralbo). Por ello, "dependiendo del tamaño, los recursos, incluso la titularidad" (Museo del Pueblo Gallego) habrá museos más vinculados que otros a los ODS.

En referencia a la integración de ejercicios sostenibles en el ámbito museístico, el Museo de Ciencias Naturales de Barcelona añade que muchos museos europeos ya los tienen incorporados en su discurso mientras que "la mayoría de los museos nacionales aún los tienen por descubrir". Sosteniendo esta idea, desde el área de difusión del Vilamuseu se enuncia que la Agenda 2030 es un tema que en España se va escuchando cada vez más en el mundo de los museos, pero menos que en otros países de Europa.

Adicionalmente, no todos los museos con mayor número de recursos abordan con la misma profundidad la Agenda 2030 puesto que en algunos se tratan "temas puntuales sobre los que montar exposiciones, actividades o líneas expositivas", mientras que en otros se inunda "toda la política del museo, sus proyectos y su forma de trabajar como entidad" (Jardín Botánico de la Universidad de Valencia). Respecto a esta desemejanza de procedimientos, el Museo del Pastor de Córdoba estima que los museos, si son públicos, programan sus actividades "siguiendo unas directrices políticas, y si son privados, siguiendo unas directrices particulares en función de sus colecciones e intereses económicos". A su vez, el Museo de Gavà enjuicia que las iniciativas emprendidas por los museos no impliquen "cambios estructurales reales y suficientes". Sobre la capacidad de decisión de los pequeños museos en cuestiones vinculadas a la sostenibilidad, el Museo Municipal de Ronda declara:

Dependemos de gobernantes que en el 99,9\% de los casos no están por la labor de hacer algo que no les suponga votos. Nos encontramos al albur de decisiones políticas, que no técnicas, para abordar estos temas en plazos que no superan los cuatro años.

Como el informe de la REDS (2020) explica, los museos del siglo XXI representan el nexo de unión entre cultura y educación por ser el espacio donde se reflejan las inquietudes de la sociedad, se estimula la alfabetización, se insta a la participación ciudadana y se genera comunidad mediante distintas formas de comunicación. De asimilarse este hecho, la cohesión de ambos aspectos, cultura y educación, puede generar una corriente cultural particular en torno a los ODS al divulgar unos conocimientos concretos e instaurar una manera de percibir el mundo.

Algunas instituciones han identificado la relevancia de la educación como: una manifestación cultural integrada en la naturaleza del museo, un medio para acercar los ODS a la población o un fin propio de la Agenda 2030 alcanzable mediante estrategias de gestión y de planificación. El Museo Laboratorium reflexiona sobre cómo "los museos tienen una mayor sensibilidad que otros agentes culturales para con el Desarrollo Sostenible" puesto que una parte fundamental de su actividad "se 
dirige a la didáctica y no al puro entretenimiento o la venta de un estilo de vida que implique el consumo masivo". Pero, de cara a los vínculos que el museo tiene con la Agenda 2030, cabe decir que los recursos educativos de la institución museística no solo pueden servir como medio de difusión de los ODS en general, sino como un fin particular al ser los museos "un pilar fundamental en la Educación para el Desarrollo Sostenible y la difusión cultural" (Museo Municipal de Antequera).

En este ejercicio resulta fundamental el lifelong learning, noción que aborda el Museo de la Ciencia de Valladolid para explicar cómo las instituciones museísticas realizan "una labor imprescindible de educación no formal". Desde este punto de vista, entre las actuaciones educativas de dicho museo, se destacan "las actividades específicas sobre los ODS gracias a que su programación está orientada a divulgar el Desarrollo Sostenible como un elemento social y cultural importante". Es decir, desarrollan sus contenidos con el fin de apoyar "a la educación sostenible y a la participación cultural".

Los museos pueden poner en práctica distintas medidas vinculadas a los ODS y, consecuentemente, notificar su colaboración en el Desarrollo Sostenible. Evidentemente si una organización desarrolla prácticas ligadas a los ODS favorecerá el Desarrollo Sostenible, pero no podrá considerarse que la institución trabaje en línea con el Desarrollo Sostenible si no lo estimula y promueve desde aquellas dimensiones que la institución atesore por su propia naturaleza. Por supuesto que es imprescindible una buena gestión de los recursos en una organización. Pero por encima de eso, los museos son espacios propicios para instaurar modelos educativos de acción que vayan a favor del desarrollo humano y comunitario. Por consiguiente, la dirección de sus actuaciones debería ir en esa línea. Esta investigación ha identificado cómo los museos contemplan el valor de su institución para la obtención del Desarrollo Sostenible en base al desempeño de estrategias de ámbito social, ambiental o económico. Pero, por lo general, no se asimila que el Museo es, per se, un actor con capacidad para fomentar el Desarrollo Sostenible. Y, sin ningún tipo de duda, esta cuestión está directamente vinculada con el hecho de que la cultura esté invisibilizada en la Agenda 2030.

\subsubsection{El escenario comunicacional en los museos}

En primer lugar, a partir de la información recogida en la investigación se comprueba que algunas instituciones museísticas aún no han interiorizado la trascendencia de contar a su público cómo son y qué es lo que hacen. En esta línea, el Museo de Nerja expresa que su foco de trabajo no se halla tanto en su comunicación como en su programación, aun estando orientada al Desarrollo Sostenible. Así declara que "el progreso del mundo se debe basar en la acción más que en la comunicación, aunque esta sea muy importante para mover conciencias. Primero actuar y después comunicar con el ejemplo".

Los grandes Museos seguramente puedan dedicar parte de sus recursos a comunicar que están haciendo los deberes, para nosotros los pequeñísimos, intentamos hacer los deberes, y comunicar que estamos aquí [...] No soy partidaria de comunicar que estoy haciendo mi trabajo, simplemente, lo hacemos (Museo del Calzado). 
En este contexto, se comenta que la difusión del vínculo que existe entre el museo y el Desarrollo Sostenible no es un objetivo troncal de la comunicación, independientemente de que esté más o menos presente en la estrategia de comunicación de la institución (Museo Nacional Centro de Arte Reina Sofía). El Desarrollo Sostenible puede ser "uno de los fines de los museos, pero no es de los principales. Por tanto, no recibe un gran cupo de visibilidad a la hora de comunicar" (Museo Cerralbo). Los motivos por los que las instituciones rechazan la existencia de un desarrollo comunicativo óptimo en los museos son variados.

El Museo Municipal Jerónimo Molina opina que "el discurso expositivo de los museos y sus actividades están montadas con criterios del siglo XX" y el Museo de la Universidad de Navarra indica que todavía el modelo de negocio de los museos solo se enfoca en lograr "su propia supervivencia". De esta forma, en muchos museos "la Agenda 2030 no está dentro de su discurso" (Museo de Ciencias Naturales de Barcelona) incluso cuando en algunos casos está presente en sus planteamientos prácticos pues, al no ser estos conocedores del papel que atesoran en la obtención de los ODS, no "son conscientes de este enfoque específico" (Museo Municipal de Antequera).

Está claro que el Desarrollo Sostenible es un tema que no puede evitarse a la hora de dar a conocer las modernizaciones, ampliaciones y novedades de los museos. Pero el objetivo de la comunicación no va en ese sentido, sino a abrir sus puertas a un mayor número de personas a través de la accesibilidad (Palacio de Gaudí).

Además, algunos museos, aun siendo conocedores del vínculo que existe entre la institución y la Agenda 2030, lo perciben como algo secundario. Por lo que no "incluyen sus Objetivos de Desarrollo Sostenible en sus políticas de comunicación" (Museo Arqueológico Provincial de Alicante) y mantienen como prioridad "la comunicación de otros muchos temas" (Museo Nacional de Arte de Cataluña) relacionados con sus fondos, su actividad o su contribución social desde una perspectiva que, aunque manida, logre atraer al mayor público posible.

La envergadura "de los ODS en la comunicación de los museos debería ser más relevante" (Museo de Santa Cruz). Sin embargo, dado que "la comunicación de una organización debe tener en cuenta los objetivos institucionales de cada momento para ser coherente con ellos" (Fundación Joan Miró), es comprensible que tan solo aquellos museos con un programa activo y específico sobre estas materias (Vilamuseu) intenten trasladar "de manera progresiva a la opinión pública, en cada comunicación, el papel que juega la institución en el ámbito del Desarrollo Sostenible" (Museo Nacional Centro de Arte Reina Sofía).

Aun así, la información aportada por las instituciones manifiesta que algunos museos comunican cuáles de sus tareas están vinculadas a la Agenda 2030, aunque no lo hagan "en clave de desarrollo, que es una clave ya elaborada, sino desde la pura información" (Museo del Retablo). Por lo que solamente indican que "algunas de sus actuaciones tienen en cuenta alguno de estos objetivos, lo que en cierta forma asocia la imagen del museo con los valores de los ODS" (Museo Valenciano de Etnología). Es decir, se indica para "eventos puntuales y con ciertas prácticas sostenibles" (Museo Evaristo Valle). 
En base a lo expresado, el Museo Picasso de Barcelona manifiesta que "sería necesario una implicación desde dirección y gerencia y que se tratara la cuestión en el plan estratégico de cada institución" para poder implicar a todos los departamentos. Por su parte, el Museo Canario indica que todavía "hay un espacio por descubrir para que los museos aprovechen el valor añadido que genera una comunicación eficaz de su contribución al Desarrollo Sostenible". Asimismo, el Museo ICO enuncia que quizás los museos podrían difundir y actuar más en esta línea si los poderes públicos impulsasen estas prácticas igual que han hecho con otras líneas estratégicas, tal y como ha ocurrido con la accesibilidad.

Además, a través de las entrevistas, se pone de manifiesto la existencia de conductas heterogéneas en el panorama museístico nacional a causa de la disimilitud de recursos entre las instituciones. Por un lado, los grandes museos con "medios y financiación suficiente" (Museo de Finestrat) elaboran una "comunicación orientada a ello" (TOPIC), mientras que la divulgación sobre el vínculo entre los museos y el Desarrollo Sostenible es más escasa en museos "que se encuentran limitados en diferentes sentidos" (Museo Histórico de Belmez y del Territorio Minero).

Tal vez esta línea de trabajo no se haya adoptado aún por los museos de una manera generalizada pero, en mayor o menor medida, los grandes museos si estamos en ello. [...] No sólo porque para nosotros sea importante, sino porque socialmente lo es y tenemos una responsabilidad pedagógica. En general los museos no le están prestando a esta comunicación la atención que merece (Museo Nacional Thyssen-Bornemisza).

Es fundamental la integración de nuestros programas con las políticas en torno al Desarrollo Sostenible de la UNESCO, el ICOM y el ICOMOS además del Consejo de Europa o la Comisión Europea. Es necesario hacer campañas a través de los museos para dar a conocer la Agenda 2030 y los ODS, y especificar de una forma clara y directa cuáles son las iniciativas generales y particulares de los museos en esta línea. Estas iniciativas se deben articular en planes, programas y proyectos concretos a corto, medio y largo plazo (Museo de Santa Cruz).

\subsubsection{La comunicación digital en los museos del territorio nacional}

Aunque las herramientas digitales contribuyen a la difusión de los Objetivos de Desarrollo Sostenible no todas las instituciones museísticas del panorama nacional disponen de estas herramientas, ni todas establecen en su programación una estrategia para el cumplimiento de los ODS, ni todas vinculan su comunicación digital al valor de sostenibilidad a pesar de que esta sea una línea transversal estratégica.

La comunicación externa, enuncia el Museo del Pueblo Gallego, es uno de los aspectos más débiles de la gestión museística a pesar de que las redes sociales e Internet hayan aportado otras herramientas de difusión como fotogrametría y reconstrucciones 3D; visitas virtuales; posicionamiento en los itinerarios; etc. Además, continúan las "dificultades para saber qué, cómo y cuándo comunicar" porque "la incorporación de profesionales especializados y de medios" es lenta (Museo de la Carolina). $Y$ es que, no todos los museos emplean los recursos posibles de la 
comunicación digital, ni para difundir todo lo que hacen, ni para divulgar cómo contribuyen al Desarrollo Sostenible (Museo Paleontológico de Alpuente).

Primero, porque "queda mucho camino para integrar los ODS en las estrategias de comunicación de los museos en general" (DOMUS) al abordar estas principalmente la difusión del museo en sí y las actividades o contenidos de sus exposiciones. Segundo, porque muchos museos tienen como asignatura pendiente "la comunicación digital en todos sus ámbitos" (Museo Municipal de Ciutadella), teniendo en cuenta que algunos centros carecen de herramientas como "páginas web actualizadas, app's, visitas virtuales, etc." (Jardín Botánico de la Universidad de Valencia). No todos los museos "tienen acceso a los mismos canales digitales" (Museo Etnológico de Tiriez) ya sea por cuestiones ligadas al tamaño y la trascendencia de la institución o a "la precariedad tanto de puestos de trabajos como de recursos, ya sean formativos 0 económicos" (Museo del Greco). De esta manera, el Museo Etnográfico Extremeño González Santana relata:

Depende mucho de la dirección del museo, de la formación de su personal, de los objetivos planteados para uno o más años. Actualmente museos como el nuestro tienen que luchar, con escasos recursos financieros, por renovar equipos tecnológicos y por estar presente en redes sociales. Todo ello a base de un esfuerzo sobrehumano, pues carecemos de personal informático especializado, restaurados, conservador, etc. Aun así, nuestra presencia en redes sociales es continua porque tenemos claro que es la mejor manera de atraer al público.

Desde el Museo de Arte Moderno y Contemporáneo de Santander y Cantabria se agrega que, en general, "la entrega y compromiso del personal que trabaja en estos museos periféricos es casi siempre muy alto, hasta heroico, muchas veces con una dedicación titánica". Los museos más pequeños suelen ser "instituciones con equipos insuficientes, precarios, y no especializados. Así que tienen carencias comunicativas en general" (Museo de Gavá). Análogamente desde el Museo Escolar de Pusol se declara que "cuando la mayor parte de museos pequeños de este país dispongan de medios, siquiera mínimos, para llevar a cabo una activa labor de difusión de la Agenda 2030, nos daremos por satisfechos".

Es decir, que los museos pequeños no emplean como deberían los recursos de comunicación digital "por la escasez de personal y consecuentemente de tiempo" (TOPIC), por la precariedad de los fondos de subvención, por la escasa colaboración y complicidad de empresas colaboradoras o por la dependencia de recursos municipales y autonómicos que les dificultan estar al día o contratar recursos con los que elaborar una sólida comunicación digital. Con lo cual, los museos con recursos, que asuman su papel en la obtención del Desarrollo Sostenible y que además dispongan de "una línea de trabajo clara y planificada", también debieran tener unas prácticas de difusión asentadas en Desarrollo Sostenible (Museo Paleontológico de Alpuente).

Los museos más 'pequeños' o no de gestión estatal, o incluso privados, pero no 'famosos' tienen más problemas para utilizar la comunicación digital, por la falta de profesionalización en el campo de la comunicación cultural digital. Hay museos que no disponen de una persona de comunicación que pueda trabajar con herramientas digitales, y otros no tienen a personal a tiempo completo que 
pueda dedicarse a ello, porque la comunicación digital, al contrario de lo que mucha gente cree, lleva su tiempo (Palacio de Gaudí).

En la Sociedad de la información los recursos digitales tienen un carácter poliédrico que "añade nuevas y enormes capacidades a la inteligencia humana y constituye un recurso que cambia la forma en que trabajamos y vivimos juntos" (Comisión Europea, 1993, p.10) por la alteración producida sobre aspectos de tipo económicos o sociales, fruto del progresivo desarrollo, así como la aplicación de las TIC y las TAC. En base a las entrevistas realizadas, se percibe la sensación general de que solamente algunos de los grandes museos españoles pueden abarcar, de una manera correcta y eficiente, la comunicación organizacional, los recursos digitales y la Agenda 2030. Las razones que motivan estas opiniones son las deficientes condiciones a las que deben enfrenarse muchos de los museos del ámbito nacional: ausencia de herramientas y canales digitales, escasos colaboradores, dependencia de recursos, precariedad de fondos, lenta incorporación de profesionales y desaprovechamiento de las redes sociales al permitir estas declinar el uso de medios de pago.

Sin embargo, el hecho de que la comunicación de un museo aborde el Desarrollo Sostenible, no depende tanto de si este dispone de recursos económicos y de personal, como si en sus líneas de planificación se incluye esta dimensión o se asume la relación natural que existe entre el museo y la Agenda 2030. Ciertamente cuantos más recursos se posean, se estima que mejor será el resultado final que se elabore, tanto por una inversión económica como de tiempo. Pero, el hecho de que el Desarrollo Sostenible no se tengan en cuenta en absoluto o que solo se vincule el museo a líneas particulares de actuación de la Agenda 2030, indica la imperiosa necesidad de que instituciones de la Administración Pública u organismos oficiales como el ICOM actúen. Es decir, no solo que insten de forma genérica a que los museos promocionen cuestiones relacionadas con el Desarrollo Sostenible, sino que desde los altos mandos se elabore un plan de concienciación y de actuación.

Por otra parte, aun abarcando la comunicación digital mucho más que las redes y los medios sociales, a lo largo de esta investigación se ha manifestado cómo el acaecimiento de la pandemia por COVID-19 ha incentivado tanto el empleo de nuevos mecanismos digitales, como el aprovechamiento de la comunicación digital en los museos. De esta forma se ha comprobado que el desarrollo de una comunicación digital a gran escala requiere planificación, personal y tiempo. Elementos que hasta el momento muchos de los grandes museos no habían tenido tan en cuenta al desatender la difusión virtual y los espacios digitales. Quizás, si continúa la tesitura ocasionada por la COVID-19, los museos logren desarrollar más estas prácticas. Posiblemente a niveles diferentes, pero de algún modo todos los museos perfeccionarían su comunicación digital creando un escenario que enalteciere al profesional de la comunicación museística en general, y dignificare la labor del comunicador digital en particular.

\section{CONCLUSIONES}

Las múltiples alusiones que vinculan la acción del museo con la vertiente educativa de la Agenda 2030 impulsan a estudiar la profunda relación entre estos y la tarea didáctica, dejando manifiesta la capacidad de las instituciones museísticas para 
contribuir al logro de los ODS. Pero, ¿se entiende la cultura como una herramienta para lograr el Desarrollo Sostenible? ¿Los museos saben que son un factor relevante para alcanzar los objetivos de la Agenda 2030? ¿Tienen las instituciones museísticas líneas de trabajo específicas sobre Desarrollo Sostenible? ¿Las estrategias de comunicación museísticas incorporan la Agenda 2030 en su discurso? De ser así, ¿tienen un fin divulgador o informativo? Con esta investigación logran alcanzarse las siguientes conclusiones.

\section{PRIMERA}

La sistematización de la Gestión Cultural pasa tanto por interiorizar que el terreno cultural albergue una función educativa con vistas a generar cohesión y desarrollo social, como por asumir que la toma de decisiones en las organizaciones tiene que ser complementaria al sistema de control y de comunicación para generar instrumentos de acción de calidad.

El transcurso de los años y las diferentes conversaciones gubernamentales internacionales han manifestado que la cultura es un impulsor y una herramienta para lograr el Desarrollo Sostenible. Sin embargo, dicha cuestión no queda patente en la Agenda 2030. El hecho de que no se visibilice la trascendencia de la cultura en general, así como la función de las industrias culturales o la misión de las instituciones culturales en particular, no solo se manifiesta negativamente en el terreno de la sostenibilidad, sino en momentos sensibles como la recesión económica de 2008 o la crisis de la COVID-19.

El impulso de la dimensión cultural de la Agenda 2030 puede contribuir a poner de manifiesto la relevancia de la cultura para la humanidad y para el planeta a fin de que se genere engagement con todas sus partes interesadas, de que se establezcan decisiones políticas y de que se emprendan actuaciones ciudadanas que salvaguarden a la cultura en todas sus formas. Por consiguiente, debe divulgarse a la ciudadanía cómo las instituciones museísticas pueden propiciar el Desarrollo Sostenible, y ha de asimilarse que los museos tienen una misión a largo plazo directamente relacionada con la sostenibilidad y la educación de calidad.

\section{SEGUNDA}

La Administración en su conjunto precisa de una comunicación externa más eficiente en el ámbito de la Agenda 2030, tanto para generar un impacto en la ciudadanía como para que sus stakeholders respalden estos objetivos. De hecho, algunas de las instituciones encuestadas demandan guías o consignas específicas sobre el tema ya que no se ha elaborado un mensaje en un tono y un estilo adecuado que haga partícipe a cada institución de su papel para la obtención del Desarrollo Sostenible. Teniendo en cuenta que existe una amplia legislación relativa a la Gestión Cultural, es preciso: primero, que desde el poder institucional se reconozca la potestad de las instituciones y las industrias culturales para llevar a cabo iniciativas que favorezcan el Desarrollo Sostenible; y segundo, que dichas entidades culturales interioricen el papel que desempeñan en el Desarrollo Sostenible, no solo para abandonar su posición rezagada respecto a la dimensión social, económica o ambiental de la Agenda 2030, 
sino para incorporar las prácticas correspondientes y difundir el lugar que ocupan en la sociedad.

\section{TERCERA}

Los museos desarrollan de forma natural muchas iniciativas que podrían contextualizarse en el marco de la sostenibilidad, pero como estos no han interiorizado los atributos de la Agenda 2030 no difunden su actuación y, por tanto, esta no alcanza a las partes interesadas. El motivo principal por el que muchos museos no divulgan su papel en los ODS se debe: primero, al desconocimiento que estas instituciones tienen sobre el espacio que ocupan en la Agenda 2030; y segundo, a que los museos no asumen el desempeño de la Agenda 2030 como una parte más de sus funciones. Consecuentemente, la relación entre el museo y el Desarrollo Sostenible no ocupa un lugar vertebral en la comunicación institucional, sino que se manifiesta de forma ocasional.

\section{CUARTA}

El talón de Aquiles de las entidades museísticas sigue siendo su comunicación organizacional. A día de hoy no todos los museos sitúan la comunicación dentro de su organigrama ni consideran necesario transmitir su filosofía y su praxis, cuando el trasvase comunicacional entre el público y una institución debe poder argumentar tanto la identidad como la ejecutoria de la misma. La relevancia de esto se halla en que el público desee formar parte de la institución museística y que la ciudadanía en general, o los stakeholders del museo en particular, quieran participar en la consecución del Desarrollo Sostenible.

Asimismo, y a pesar de que la UNESCO (2015) haya señalado que la comunicación de los museos es crucial para impulsar su acción social, se detecta que muchas de las entidades museísticas asumen que comunicar solo implica informar, que se reclama personal que nutra y desarrolle los Departamentos de Comunicación de los museos y que aún se requiere de la profesionalización de la actividad comunicativa en las instituciones museísticas para que las personas responsables tengan la preparación suficiente y puedan estar ligadas a los puestos de alta dirección.

\section{QUINTA}

En el panorama nacional coexisten:

- Museos que no disponen de una estrategia sólida de comunicación, bien por precariedad de recursos y personal, bien porque aún no se considere relevante esta dimensión en la institución.

- Museos que sí disponen de una estrategia de comunicación pero no en el ámbito digital, ya sea por motivos similares al aspecto anterior o porque el museo estime que dichas prácticas se reducen al uso de redes sociales 0 espacios web sin aludir a las tecnologías para el aprendizaje continuo, capaces de contribuir a que la ciudadanía integre la Agenda 2030 mediante multitud de estrategias online.

- Museos que sí disponen de una estrategia sólida de comunicación, incluida su dimensión digital, pero que no integran dentro de su programación al Desarrollo 
Sostenible ya sea por no tener en cuenta la Agenda 2030 dentro de sus funciones o por considerarla como una cuestión tangencial.

- Museos que integran políticas de comunicación, una estrategia de comunicación digital y un vínculo entre sus funciones y el Desarrollo Sostenible.

\section{SEXTA}

Se considera relevante poder estudiar a hechos consumados si el caso de la COVID19 ha logrado impulsar la comunicación digital externa del museo en España, tanto desde una perspectiva corporativa como de difusión cultural, y conocer si su narrativa hipermedia y transmedia favorece la Educación para el Desarrollo Sostenible.

\section{REFERENCIAS}

Berganza, M. R. y Ruiz J. A. (Eds.). (2005). Investigar en Comunicación: Guía práctica de métodos y técnicas de investigación social en comunicación. Madrid, España: McGraw Hill.

Canel, M. J. (2018). La comunicación en la Administración Pública. Para gobernar con la sociedad. Ciudad de México, México: Fondo de lectura económica.

Canel, M. J. y Luoma-aho, V. (2017). ¿Qué aportan los bienes intangibles a la administración pública? En Canel, M. J., Piqueiras, P., Ortega, G. (Eds.), La comunicación de la Administración Pública: conceptos y casos prácticos de bienes intangibles (pp.29-50). Madrid, España: Innap Investiga.

CM Málaga. (2020). Nuevos retos para la cultura y el turismo. Museos y ciudades ante la revolución digital de la era post-covid [Video]. https://cdn.ireland.production.livestorm.io/uploads/media/file/6adc37ff-ddcc-43be98aa-e93e7b6f5f4a/88c3966e-5cc3-4159-95655b74bbf34559.mp4?v=1592842528

Comisión Europea (1993). Report on Europe and the global information society. http://aei.pitt.edu/1199/1/info society bangeman report.pdf

Consejo Internacional de Museos (ICOM). (2020a). Los Objetivos de Desarrollo Sostenible: ayudar a transformar nuestro mundo a través de los museos. https://icom.museum/es/news/los-objetivos-de-desarrollo-sostenible-ayudar-atransformar-nuestro-mundo-a-traves-de-los-museos/

Consejo Internacional de Museos (ICOM). (2020b). Definir el museo en tiempos de cambio: un camino a seguir. https://www.yuca.tv/es/icom/defining-the-museum-intimes-of-change-a-way-forward

García-Nieto, M. T., Viñarás-Abad, M. y Cabezuelo-Lorenzo, F. (2020). Medio siglo de evolución del concepto de Relaciones Públicas (1970-2020). El profesional de la infromación, 29 (3), e290319. https://doi.org/10.3145/epi.2020.may.19 
Hernández, F. (2018). Reflexiones museológicas desde los márgenes. Gijón, España: Trea.

Hurstand, B. y Ihlen, Ø. (2018). Corporate Social Responsibility and Engagement Commitment, Mapping of Responsibilities, and Closing the Loop. En Johnston, K. A. y Taylor, M. (Ed), The Handbook of Communication Engagement (pp.133-147). Hoboken, Estados Unidos: Wiley-Blackwel.

Johnston, K. A. (2018). Toward a Theory of Social Engagement. En Johnston, K. A. y Taylor, M. (Ed), The Handbook of Communication Engagement (pp.19-32). Hoboken, Estados Unidos: Wiley-Blackwel.

La Organización de las Naciones Unidas para la Educación, la Ciencia y la Cultura (UNESCO). (2015). Recomendación relativa a la protección y promoción de los museos y colecciones, su diversidad y su función en la sociedad. https://unesdoc.unesco.org/ark:/48223/pf0000246331

La Organización de las Naciones Unidas para la Educación, la Ciencia y la Cultura (UNESCO). (2017). Informe de Seguimiento de la Educación en el Mundo 2016. La educación al servicio de los pueblos y el planeta. https://unesdoc.unesco.org/ark:/48223/pf0000248526/PDF/248526spa.pdf.multi

La Organización de las Naciones Unidas para la Educación, la Ciencia y la Cultura (UNESCO). (2020). La UNESCO y el ICOM preocupados por la situación de los museos del mundo. https://es.unesco.org/news/unesco-y-icom-preocupadossituacion-museos-del-mundo

Llerena, S. (2015). La comunicación de los museos españoles en Twitter: análisis de la situación y establecimiento de buenas prácticas. (Tesis doctoral). Universidad Carlos III de Madrid, Madrid, España.

Mas Iglesias, J. M. (2019). Museos españoles en Facebook: análisis de su comunicación en el marco del museo social digital. (Tesis doctoral). Universidad Carlos III de Madrid, Madrid, España.

Mateos, S. M. (2012). Manual de comunicación para museos y atractivos patrimoniales. Gijón, España: Trea.

McGhie, H. A. (2019). Museums and the Sustainable Development Goals: a how toguide for museums, galleries, the cultural sector and their partners. Curating Tomorrow, UK. http://www.curatingtomorrow.co.uk/wpcontent/uploads/2020/01/museums-and-the-sustainable-development-goals2019.pdf

Ministerio de Cultura y Deporte. (s.f.). Directorio de museos. http://directoriomuseos.mcu.es/dirmuseos/mostrarBusquedaGeneral.do 
Moreno, I. (2005). Nuevas Tecnologías, nuevas formas de difusión del conocimiento. Museo: Revista de la Asociación Profesional de Museólogos de España, 10, 233243.

Red Española para el Desarrollo Sostenible (REDS). (2020). Cultura y Desarrollo Sostenible. Aportaciones al debate sobre la dimensión cultural de la Agenda 2030. https://reds-sdsn.es/nueva-publicacion-cultura-desarrollo-sostenible

Rivero, M. P. (2010). Cibermuseología interactiva on line. En J. Santacana Mestre y C. Martín Piñol, Manual de museografía interactiva (pp. 369-390). Gijón, España: Trea.

Viñarás, M. (2005). La gestión de la comunicación en los museos de Madrid: auditoria de relaciones públicas (Tesis doctoral). Universidad Complutense, Madrid, España.

Viñarás, M. (2016). La importancia de la identidad corporativa en el diálogo con los públicos en el sector cultural: el caso de los museos especializado. En K. Matilla. (Ed.), Casos de estudio de las Relaciones Públicas. Espacios de diálogo e impacto mediático (pp. 95-132). Barcelona, España: UOC.

\section{AUTORAS}

\section{Emma Gabriela Carbonell-Curralo}

Periodista especializada en Comunicación de las Organizaciones con experiencia profesional en equipos dedicados a la asistencia y el desarrollo comunitario. Su área de acción es la sanitaria y la cultural, así como el ámbito digital.

Orcid ID: https://orcid.org/0000-0001-8879-6581

Google Scholar: EMMA G. CARBONELL CURRALO - Google Scholar

\section{Mónica Viñarás Abad}

Doctora por la Universidad Complutense de Madrid. Sus líneas de investigación y docencia se centran en la gestión de la comunicación y las relaciones públicas, el sector cultural, la gestión de los intangibles y la Responsabilidad Social Corporativa.

Orcid ID: https://orcid.org/0000-0001-8792-5927

Google Scholar: Mónica Viñarás - Google Scholar 


\section{ANEXO}

Tabla 1. Museos que han formado parte del estudio

\begin{tabular}{|c|c|}
\hline ANDALUCÍA & \\
\hline Almería & 1. Museo Histórico Municipal de Terque \\
\hline Córdoba & $\begin{array}{l}\text { 2. Casa-Museo de Artes y Costumbres Populares de Castil de Campos } \\
\text { 3. Museo Arqueológico y Etnológico de Lucena } \\
\text { 4. Museo de Historia Local de Villanueva de Córdoba } \\
\text { 5. Museo del Pastor de Villaralto } \\
\text { 6. Museo Histórico de Belmez y del Territorio Minero } \\
\text { 7. Museo Histórico Municipal de Cañete de las Torres } \\
\text { 8. Museo Vivo de Al-Andalus Torre de la Calahorra }\end{array}$ \\
\hline $\begin{array}{l}\text { Granada } \\
\text { Jaén }\end{array}$ & $\begin{array}{l}\text { 9. Centro de Arte José Guerrero } \\
\text { 10. Museo de la Carolina Capital de las Nuevas Poblaciones } \\
\text { 11. Museo Íbero }\end{array}$ \\
\hline Málaga & $\begin{array}{l}\text { 12. Museo de Nerja } \\
\text { 13. Museo Municipal de Antequera } \\
\text { 14. Museo Municipal de Ronda } \\
\text { 15. Museo Picasso Málaga }\end{array}$ \\
\hline ARAGÓN & \\
\hline Huesca & 16. Museo de Dibujo Julio Gavin-Castillo de Larrés \\
\hline Teruel & $\begin{array}{l}\text { 17. Museo Aragonés de Paleontología } \\
\text { 18. Museo-Exposición Permanente Monoaráfica del Azafrán }\end{array}$ \\
\hline Zaragoza & 19. Museo del Fuego y de los Bomberos \\
\hline CANARIAS & \\
\hline Las Palmas & 20. El Museo Canario \\
\hline CANTABRIA & \\
\hline & $\begin{array}{l}\text { 21. Museo de la Naturaleza de Cantabria } \\
\text { 22. Museo de Arte Moderno y Contemporáneo de Santander y Cantabria }\end{array}$ \\
\hline $\begin{array}{l}\text { CASTILLA Y } \\
\text { LEÓN }\end{array}$ & \\
\hline Burgos & $\begin{array}{l}\text { 23. Museo de la Evolución Humana } \\
\text { 24. Museo del Retablo }\end{array}$ \\
\hline León & 25. Palacio de Gaudí - Museo de los Caminos \\
\hline Salamanca & 26. Museo de Salamanca \\
\hline Segovia & 27. Casa Museo Antonio Machado \\
\hline Valladolid & $\begin{array}{l}\text { 28. Museo de la Ciencia de Valladolid } \\
\text { 29. Museo del Monasterio de San Joaquín y Santa Ana }\end{array}$ \\
\hline $\begin{array}{l}\text { CASTILLA-LA } \\
\text { MANCHA }\end{array}$ & \\
\hline Albacete & $\begin{array}{l}\text { 30. Museo Etnológico de Tiriez } \\
\text { 31. Museo Municipal de la Cuchillería } \\
\text { 32. Museo Pedagógico y del Niño }\end{array}$ \\
\hline Cuenca & 33. Museo de Cuenca \\
\hline Toledo & $\begin{array}{l}\text { 34. Museo del Greco } \\
\text { 35. Museo Etnográfico de Talavera de la Reina } \\
\text { 36. Museo la Celestina } \\
\text { 37. Museo Sefardí } \\
\text { 38. Museo de Santa Cruz }\end{array}$ \\
\hline CATALUÑA & \\
\hline Barcelona & $\begin{array}{l}\text { 39. Biblioteca Museo Víctor Balaguer } \\
\text { 40. Fundación Joan Miró } \\
\text { 41. Museo de Ciencias Naturales de Barcelona } \\
\text { 42. Museo de Gavà } \\
\text { 43. Museo de Museo de la Payesía de Castellbisbal } \\
\text { 44. Museo Frederic Marès }\end{array}$ \\
\hline
\end{tabular}




\begin{tabular}{|c|c|}
\hline Tarragona & $\begin{array}{l}\text { 45. Museo Geológico del Seminario de Barcelona } \\
\text { 46. Museo Marítimo de Barcelona } \\
\text { 47. Museo Nacional de Arte de Cataluña } \\
\text { 48. Museo Picasso } \\
\text { 49. Museo Romántico Can Papiol } \\
\text { 50. Fundación Apel·les Fenosa } \\
\text { 51. Museo Diocesano de Tarragona }\end{array}$ \\
\hline $\begin{array}{l}\text { COMUNIDAD } \\
\text { DE MADRID } \\
\text { Madrid }\end{array}$ & $\begin{array}{l}\text { 52. Museo Cerralbo } \\
\text { 53. Museo de Aeronáutica y Astronáutica } \\
\text { 54. Museo de Bomberos } \\
\text { 55. Museo de Historia de Madrid } \\
\text { 56. Museo de la Cantería al Aire Libre } \\
\text { 57. Museo de la Farmacia Hispana } \\
\text { 58. Museo del Cine } \\
\text { 59. Museo del Traje. CIPE } \\
\text { 60. Museo ICO } \\
\text { 61. Museo Nacional Centro de Arte Reina Sofía } \\
\text { 62. Museo Nacional de Antropología } \\
\text { 63. Museo Nacional de Artes Decorativas } \\
\text { 64. Museo Nacional Thyssen-Bornemisza } \\
\text { 65. Museo Naval } \\
\text { 66. Museo Pedagógico de Arte Infantil } \\
\text { 67. Museo Tiflológico }\end{array}$ \\
\hline $\begin{array}{l}\text { COMUNIDAD } \\
\text { FORAL DE } \\
\text { NAVARRA } \\
\text { Pamplona }\end{array}$ & $\begin{array}{l}\text { 68. Museo de Navarra } \\
\text { 69. Museo de Tudela } \\
\text { 70. Museo de la Universidad de Navarra }\end{array}$ \\
\hline $\begin{array}{l}\text { COMUNIDAD } \\
\text { VALENCIANA } \\
\text { Alicante }\end{array}$ & $\begin{array}{l}\text { 71. Centro de Cultura Tradicional Museo Escolar de Pusol } \\
\text { 72. Fundación La Alcudia } \\
\text { 73. Museo Arqueológico de Elda } \\
\text { 74. Museo Arqueológico Provincial de Alicante } \\
\text { 75. Museo de Finestrat } \\
\text { 76. Museo del Calzado } \\
\text { 77. Museo Nueva Tabarca } \\
\text { 78. Vilamuseu } \\
\text { 79. Museo de la Valltorta } \\
\text { 80. Jardín Botánico de la Universidad de Valencia } \\
\text { 81. Museo de Bellas Artes de Valencia } \\
\text { 82. Museo de las Ciencias } \\
\text { 83. Museo Etnológico Cacharrería de Ángel Domínguez } \\
\text { 84. Museo Internacional de Títeres de Albaida } \\
\text { 85. Museo Municipal de Historia y Arqueología de Cullera } \\
\text { 86. Museo Paleontológico de Alpuente } \\
\text { 87. Museo Valenciano de Etnología }\end{array}$ \\
\hline $\begin{array}{l}\text { EXTREMADURA } \\
\text { Cáceres } \\
\text { Badajoz }\end{array}$ & $\begin{array}{l}\text { 88. Museo del Queso } \\
\text { 89. Museo Fundación Pecharromán } \\
\text { 90. Consorcio Museo Etnográfico Extremeño González Santana } \\
\text { 91. Museo Arqueológico Provincial } \\
\text { 92. Museo Extremeño e Iberoamericano de Arte Contemporáneo } \\
\text { 93. Museo Nacional de Arte Romano }\end{array}$ \\
\hline $\begin{array}{l}\text { GALICIA } \\
\text { A Coruña }\end{array}$ & Científicos Coruñeses \\
\hline
\end{tabular}




\begin{tabular}{|c|c|}
\hline $\begin{array}{l}\text { Ourense } \\
\text { Pontevedra }\end{array}$ & $\begin{array}{l}\text { 95. Museo del Pueblo Gallego } \\
\text { 96. Museo Granell } \\
\text { 97. Museo Etnológico de Ribadavia } \\
\text { 98. Museo Provincial de Pontevedra }\end{array}$ \\
\hline $\begin{array}{l}\text { ISLAS } \\
\text { BALEARES } \\
\text { Menorca }\end{array}$ & 99. Museo Municipal de Ciutadella \\
\hline $\begin{array}{l}\text { LA RIOJA } \\
\text { La Rioja }\end{array}$ & 100.Fundación Museo Histórico Arqueológico Najerillense \\
\hline $\begin{array}{l}\text { PAÍS VASCO } \\
\text { Guipúzcoa }\end{array}$ & $\begin{array}{l}\text { 101. Caserío Museo Igartubeiti } \\
\text { 102. Ekainberri } \\
\text { 103. Eureka! Zientzia Museoa } \\
\text { 104. Museo Ibarraundi } \\
\text { 105. Museo Laboratorium } \\
\text { 106. TOPIC, Centro Internacional del Títere de Tolosa } \\
\text { 107. Hontza Museo } \\
\text { 108. Museo de Arte Sacro } \\
\text { 109. Museo Guggenheim Bilbao }\end{array}$ \\
\hline $\begin{array}{l}\text { PRINCIPADO } \\
\text { DE ASTURIAS } \\
\text { Asturias }\end{array}$ & $\begin{array}{l}\text { 110. Museo Barjola } \\
\text { 111. Museo Evaristo Valle } \\
\text { 112. Museo Marítimo de Asturias }\end{array}$ \\
\hline $\begin{array}{l}\text { REGIÓN DE } \\
\text { MURCIA } \\
\text { Murcia }\end{array}$ & $\begin{array}{l}\text { 113. Museo Arqueológico Municipal de Cehegín } \\
\text { 114. Museo Municipal Jerónimo Molina }\end{array}$ \\
\hline
\end{tabular}

Fuente: Elaboración propia a partir de las respuestas aportadas 
Tabla 2. Resumen de respuestas de los museos del territorio nacional.

\begin{tabular}{|c|c|c|c|c|c|}
\hline Institución & 1 & 2 & 3 & 4 & 5 \\
\hline $\begin{array}{l}\text { Museo Histórico Municipal de } \\
\text { Terque }\end{array}$ & No & Sí & Sí & Sí & Sí \\
\hline $\begin{array}{l}\text { Casa-Museo de Artes y } \\
\text { Costumbres Populares de Castil } \\
\text { de Campos }\end{array}$ & No & Sí & Sí & Sí & Sí \\
\hline $\begin{array}{l}\text { Museo Arqueológico y Etnológico } \\
\text { de Lucena }\end{array}$ & No & Sí & Sí & No & No \\
\hline $\begin{array}{l}\text { Museo de Historia Local de } \\
\text { Villanueva de Córdoba }\end{array}$ & Sí & Sí & Sí & No & No \\
\hline Museo del Pastor de Villaralto & No & No & No & No & No \\
\hline $\begin{array}{l}\text { Museo Histórico de Belmez y del } \\
\text { Territorio Minero }\end{array}$ & No & Sí & No & Sí & No \\
\hline $\begin{array}{l}\text { Museo Histórico Municipal de } \\
\text { Cañete de las Torres }\end{array}$ & No & Sí & Sí & No & No \\
\hline $\begin{array}{l}\text { Museo Vivo de Al-Andalus Torre } \\
\text { de la Calahorra }\end{array}$ & Sí & Sí & Sí & No & No \\
\hline Centro de Arte José Guerrero & Sí & Sí & Sí & No & No \\
\hline $\begin{array}{l}\text { Museo de la Carolina Capital de } \\
\text { las Nuevas Poblaciones }\end{array}$ & No & Sí & Sí & No & Sí \\
\hline Museo Íbero & Sí & Sí & Sí & No & No \\
\hline Museo de Nerja & Sí & Sí & Sí & No & No \\
\hline Museo Municipal de Antequera & Sí & Sí & Sí & No & No \\
\hline Museo Municipal de Ronda & Sí & Sí & No & No & No \\
\hline Museo Picasso Málaga & Sí & Sí & Sí & No & Sí \\
\hline $\begin{array}{l}\text { Museo de Dibujo Julio Gavin- } \\
\text { Castillo de Larrés }\end{array}$ & Sí & Sí & Sí & No & No \\
\hline $\begin{array}{l}\text { Museo Aragonés de } \\
\text { Paleontología }\end{array}$ & Sí & Sí & Sí & Sí & No \\
\hline $\begin{array}{l}\text { Museo-Exposición Permanente } \\
\text { Monográfica del Azafrán }\end{array}$ & Sí & Sí & No & No & No \\
\hline $\begin{array}{l}\text { Museo del Fuego y de los } \\
\text { Bomberos }\end{array}$ & Sí & Sí & No & No & No \\
\hline El Museo Canario & Sí & Sí & Sí & No & No \\
\hline $\begin{array}{l}\text { Museo de la Naturaleza de } \\
\text { Cantabria }\end{array}$ & Sí & Sí & Sí & No & No \\
\hline $\begin{array}{l}\text { Museo de Arte Moderno y } \\
\text { Contemporáneo de Santander y } \\
\text { Cantabria }\end{array}$ & Sí & Sí & Sí & Sí & Sí \\
\hline Museo de la Evolución Humana & Sí & Sí & Sí & No & No \\
\hline Museo del Retablo & Sí & Sí & Sí & No & No \\
\hline $\begin{array}{l}\text { Palacio de Gaudí - Museo de los } \\
\text { Caminos }\end{array}$ & Sí & Sí & Sí & No & No \\
\hline Museo de Salamanca & No & $\begin{array}{l}\text { No lo } \\
\text { sabe }\end{array}$ & No & No & No \\
\hline Casa Museo Antonio Machado & Sí & Sí & Sí & No & No \\
\hline Museo de la Ciencia de Valladolid & Sí & Sí & Sí & No & Sí \\
\hline $\begin{array}{l}\text { Museo del Monasterio de San } \\
\text { Joaquín y Santa Ana }\end{array}$ & Sí & Sí & Sí & Sí & Sí \\
\hline Museo Etnológico de Tiriez & Sí & Sí & Sí & Sí & No \\
\hline Museo Municipal de la Cuchillería & Sí & Sí & No & No & No \\
\hline Museo Pedagógico y del Niño & Sí & Sí & Sí & No & Sí \\
\hline Museo de Cuenca & No & Sí & No & Sí & No \\
\hline Museo del Greco & Sí & Sí & Sí & No & Sí \\
\hline
\end{tabular}


MUSEOS Y DESARROLLO SOSTENIBLE. GESTIÓN MUSEÍSTICA Y COMUNICACIÓN DIGITAL PARA ALCANZAR LOS ODS

\begin{tabular}{|c|c|c|c|c|c|}
\hline $\begin{array}{l}\text { Museo Etnográfico de Talavera } \\
\text { de la Reina }\end{array}$ & Sí & Sí & Sí & Sí & Sí \\
\hline Museo la Celestina & Sí & Sí & Sí & Sí & Sí \\
\hline Museo Sefardí & Sí & Sí & Sí & Sí & Sí \\
\hline Museo de Santa Cruz & Sí & Sí & Sí & Sí & No \\
\hline Biblioteca Museo Víctor Balaguer & No & Sí & Sí & Sí & No \\
\hline Fundación Joan Miró & Sí & Sí & Sí & Sí & Sí \\
\hline $\begin{array}{l}\text { Museo de Ciencias Naturales de } \\
\text { Barcelona }\end{array}$ & Sí & Sí & Sí & No & No \\
\hline Museo de Gavà & Sí & Sí & Sí & No & No \\
\hline $\begin{array}{l}\text { Museo de Museo de la Payesía } \\
\text { de Castellbisbal }\end{array}$ & No & Sí & No & No & No \\
\hline Museo Frederic Marès & Sí & Sí & No & Sí & Sí \\
\hline $\begin{array}{l}\text { Museo Geológico del Seminario } \\
\text { de Barcelona }\end{array}$ & No & Sí & Sí & No & Sí \\
\hline Museo Marítimo de Barcelona & Sí & Sí & Sí & Sí & No \\
\hline $\begin{array}{l}\text { Museo Nacional de Arte de } \\
\text { Cataluña }\end{array}$ & Sí & Sí & Sí & No & No \\
\hline Museo Picasso & Sí & Sí & Sí & No & No \\
\hline Museo Romántico Can Papiol & No & Sí & Sí & Sí & No \\
\hline Fundación Apel·les Fenosa & Sí & Sí & Sí & Sí & No \\
\hline Museo Diocesano de Tarragona & No & Sí & No & No & No \\
\hline Museo Cerralbo & Sí & Sí & Sí & Sí & Sí \\
\hline $\begin{array}{l}\text { Museo de Aeronáutica y } \\
\text { Astronáutica }\end{array}$ & Sí & Sí & Sí & Sí & Sí \\
\hline Museo de Bomberos & Sí & Sí & Sí & No & No \\
\hline Museo de Historia de Madrid & Sí & Sí & Sí & No & No \\
\hline Museo de la Cantería al Aire Libre & Sí & Sí & Sí & Sí & Sí \\
\hline Museo de la Farmacia Hispana & No & Sí & No & No & No \\
\hline Museo del Cine & No & Sí & No & No & No \\
\hline Museo del Traje. CIPE & Sí & Sí & Sí & No & No \\
\hline Museo ICO & Sí & Sí & Sí & Sí & Sí \\
\hline $\begin{array}{l}\text { Museo Nacional Centro de Arte } \\
\text { Reina Sofía }\end{array}$ & Sí & Sí & Sí & Sí & Sí \\
\hline Museo Nacional de Antropología & Sí & Sí & Sí & Sí & Sí \\
\hline $\begin{array}{l}\text { Museo Nacional de Artes } \\
\text { Decorativas }\end{array}$ & Sí & Sí & Sí & Sí & No \\
\hline $\begin{array}{l}\text { Museo Nacional Thyssen- } \\
\text { Bornemisza }\end{array}$ & Sí & Sí & Sí & Sí & Sí \\
\hline Museo Naval & Sí & Sí & Sí & Sí & Sí \\
\hline $\begin{array}{l}\text { Museo Pedagógico de Arte } \\
\text { Infantil }\end{array}$ & Sí & Sí & Sí & No & Sí \\
\hline Museo Tiflológico & Sí & Sí & Sí & $\begin{array}{l}\text { No lo } \\
\text { sabe }\end{array}$ & Sí \\
\hline Museo de Navarra & Sí & Sí & Sí & No & No \\
\hline Museo de Tudela & Sí & Sí & Sí & No & No \\
\hline $\begin{array}{l}\text { Museo de la Universidad de } \\
\text { Navarra }\end{array}$ & Sí & Sí & Sí & No & No \\
\hline $\begin{array}{l}\text { Centro de Cultura Tradicional } \\
\text { Museo Escolar de Pusol }\end{array}$ & Sí & Sí & Sí & Sí & Sí \\
\hline Fundación La Alcudia & Sí & Sí & No & No & No \\
\hline Museo Arqueológico de Elda & No & Sí & No & No & No \\
\hline $\begin{array}{l}\text { Museo Arqueológico Provincial de } \\
\text { Alicante }\end{array}$ & Sí & Sí & Sí & No & Sí \\
\hline Museo de Finestrat & No & Sí & Sí & Sí & No \\
\hline
\end{tabular}




\begin{tabular}{|c|c|c|c|c|c|}
\hline Museo del Calzado & Sí & Sí & Sí & Sí & Sí \\
\hline Museo Nueva Tabarca & Sí & Sí & Sí & Sí & Sí \\
\hline Vilamuseu & Sí & Sí & No & Sí & No \\
\hline Museo de la Valltorta & No & Sí & No & No & No \\
\hline $\begin{array}{l}\text { Jardín Botánico de la Universidad } \\
\text { de Valencia }\end{array}$ & Sí & Sí & No & No & Sí \\
\hline $\begin{array}{l}\text { Museo de Bellas Artes de } \\
\text { Valencia }\end{array}$ & Sí & Sí & Sí & Sí & Sí \\
\hline Museo de las Ciencias & Sí & Sí & Sí & Sí & Sí \\
\hline $\begin{array}{l}\text { Museo Etnológico Cacharrería de } \\
\text { Ángel Domínguez }\end{array}$ & Sí & No & Sí & No & No \\
\hline $\begin{array}{l}\text { Museo Internacional de Títeres de } \\
\text { Albaida }\end{array}$ & Sí & Sí & Sí & Sí & No \\
\hline $\begin{array}{l}\text { Museo Municipal de Historia y } \\
\text { Arqueología de Cullera }\end{array}$ & Sí & Sí & Sí & Sí & Sí \\
\hline $\begin{array}{l}\text { Museo Paleontológico de } \\
\text { Alpuente }\end{array}$ & Sí & Sí & No & Sí & Sí \\
\hline Museo Valenciano de Etnología & Sí & Sí & Sí & No & No \\
\hline $\begin{array}{l}\text { Museo del Queso de Casar de } \\
\text { Cáceres }\end{array}$ & Sí & Sí & Sí & Sí & No \\
\hline Museo Fundación Pecharromán & Sí & Sí & Sí & Sí & Sí \\
\hline $\begin{array}{l}\text { Consorcio Museo Etnográfico } \\
\text { Extremeño González Santana }\end{array}$ & Sí & Sí & Sí & No & No \\
\hline $\begin{array}{l}\text { Museo Arqueológico Provincial de } \\
\text { Badajoz }\end{array}$ & Sí & Sí & No & No & No \\
\hline $\begin{array}{l}\text { Museo Extremeño e } \\
\text { lberoamericano de Arte } \\
\text { Contemporáneo }\end{array}$ & Sí & Sí & No & No & No \\
\hline Museo Nacional de Arte Romano & Sí & Sí & Sí & Sí & No \\
\hline DOMUS & Sí & Sí & Sí & Sí & No \\
\hline Museo del Pueblo Gallego & Sí & Sí & Sí & No & No \\
\hline Museo Granell & Sí & Sí & Sí & No & No \\
\hline Museo Etnológico de Ribadavia & Sí & Sí & Sí & No & No \\
\hline Museo Provincial de Pontevedra & Sí & Sí & Sí & No & Sí \\
\hline Museo Municipal de Ciutadella & No & Sí & Sí & No & No \\
\hline $\begin{array}{l}\text { Fundación Museo Histórico } \\
\text { Arqueológico Najerillense }\end{array}$ & No & Sí & Sí & No & No \\
\hline Caserío Museo Igartubeiti & No & Sí & No & Sí & No \\
\hline Ekainberri & Sí & Sí & Sí & Sí & Sí \\
\hline Eureka! Zientzia Museoa & No & Sí & Sí & Sí & Sí \\
\hline Museo Ibarraundi & No & Sí & Sí & $\begin{array}{l}\text { No lo } \\
\text { sabe }\end{array}$ & No \\
\hline Museo Laboratorium & No & Sí & Sí & No & No \\
\hline TOPIC & Sí & Sí & Sí & Sí & No \\
\hline Hontza Museo & Sí & Sí & Sí & Sí & No \\
\hline Museo de Arte Sacro & No & No & Sí & No & No \\
\hline Museo Guggenheim Bilbao & Sí & Sí & Sí & Sí & Sí \\
\hline Museo Barjola & Sí & Sí & No & Sí & No \\
\hline Museo Evaristo Valle & Sí & Sí & No & No & No \\
\hline Museo Marítimo de Asturias & No & Sí & Sí & No & No \\
\hline $\begin{array}{l}\text { Museo Arqueológico Municipal de } \\
\text { Cehegín }\end{array}$ & Sí & Sí & Sí & Sí & No \\
\hline Museo Municipal Jerónimo Molina & No & Sí & No & No & No \\
\hline
\end{tabular}

Fuente: Elaboración propia a partir de las respuestas aportadas 


\section{MUSEOS Y DESARROLLO SOSTENIBLE. GESTIÓN MUSEÍSTICA Y COMUNICACIÓN DIGITAL PARA ALCANZAR LOS ODS}

Tabla 3. Museos participantes del territorio nacional que desconocen la Agenda 2030 y los ODS.

\begin{tabular}{|c|c|c|}
\hline Institución & Titularidad & Gestión \\
\hline Museo Histórico Municipal de Terque & blica - Ayuntamiento & blica - Ayuntamiento \\
\hline $\begin{array}{l}\text { Casa Museo de Artes y Costumbres } \\
\text { populares de Castil de Campos }\end{array}$ & $\begin{array}{l}\text { Privada - Asociación } \\
\text { Cultural de Castil de } \\
\text { Campos } \\
\end{array}$ & $\begin{array}{l}\text { vada-Asociación Cultural } \\
\text { de Castil de Campos }\end{array}$ \\
\hline $\begin{array}{l}\text { Museo Arqueológico y Etnológico de } \\
\text { Lucena }\end{array}$ & blica - Ayuntamiento & blica - Ayuntamiento \\
\hline Museo del Pastor de Villarato & blica - Ayuntamiento & blica - Ayuntamiento \\
\hline $\begin{array}{l}\text { Museo Histórico de Belmez y del } \\
\text { Territorio Minero }\end{array}$ & blica - Ayuntamiento & blica - Ayuntamiento \\
\hline $\begin{array}{l}\text { Museo Histórico Municipal de Cañete } \\
\text { de las Torres }\end{array}$ & blica - Ayuntamiento & blica - Ayuntamiento \\
\hline $\begin{array}{l}\text { Museo de la Carolina Capital de las } \\
\text { Nuevas Poblaciones }\end{array}$ & blica - Ayuntamiento & blica - Ayuntamiento \\
\hline Museo de Salamanca & $\begin{array}{l}\text { blica - Ministerio de Cultura } \\
\text { y Deporte }\end{array}$ & $\begin{array}{l}\text { blica - Consejería o } \\
\text { Departamento de Cultura }\end{array}$ \\
\hline Museo de Cuenca & $\begin{array}{l}\text { blica - Ministerio de Cultura } \\
\text { y Deporte }\end{array}$ & $\begin{array}{l}\text { blica - Consejería o } \\
\text { Departamento de Cultura }\end{array}$ \\
\hline Biblioteca Museo Víctor Balaguer & blica - Ayuntamiento & blica - Ayuntamiento \\
\hline Museo de la Payesía de Castellbisbal & blica - Ayuntamiento & blica - Ayuntamiento \\
\hline $\begin{array}{l}\text { Museo Geológico del Seminario De } \\
\text { Barcelona }\end{array}$ & $\begin{array}{l}\text { vada - Instituciones } \\
\text { Religiosas }\end{array}$ & $\begin{array}{l}\text { vada - Instituciones } \\
\text { Religiosas }\end{array}$ \\
\hline Museo Romántico Can Papiol & blica - Ayuntamiento & blica - Ayuntamiento \\
\hline Museo Diocesano de Tarragona & $\begin{array}{l}\text { vada - Instituciones } \\
\text { Religiosas }\end{array}$ & $\begin{array}{l}\text { vada - Instituciones } \\
\text { Religiosas }\end{array}$ \\
\hline Museo de la Farmacia Hispana & blica - Universidad & blica - Universidad \\
\hline Museo del Cine & vada - Persona física & vada - Persona física \\
\hline Museo Arqueológico de Elda & blica - Ayuntamiento & blica - Ayuntamiento \\
\hline Museo de Finestrat & blica - Ayuntamiento & blica - Ayuntamiento \\
\hline Museo de la Valltorta & $\begin{array}{l}\text { blica - Consejería o } \\
\text { Departamento de Cultura }\end{array}$ & $\begin{array}{l}\text { blica - Consejería o } \\
\text { Departamento de Cultura }\end{array}$ \\
\hline Museo Municipal de Ciutadella & blica - Ayuntamiento & blica - Ayuntamiento \\
\hline $\begin{array}{l}\text { Fundación Museo Histórico } \\
\text { Arqueológico Najerillense }\end{array}$ & $\begin{array}{l}\text { vada - Persona jurídica } \\
\text { (Fundación) }\end{array}$ & $\begin{array}{l}\text { ta/Compartida - Varios } \\
\text { organismos públicos y } \\
\text { privados }\end{array}$ \\
\hline Caserío Museo Igartubeiti & $\begin{array}{l}\text { blica - Diputación Foral de } \\
\text { Gipuzkoa }\end{array}$ & $\begin{array}{l}\text { vada - Persona jurídica } \\
\text { (Empresa K6 Gestión } \\
\text { Cultural) }\end{array}$ \\
\hline Eureka! Zientzia Museoa & vada - Otra & vada - Otra \\
\hline
\end{tabular}


Emma Gabriela Carbonell-Curralo y Mónica Viñarás Abad

\begin{tabular}{|l|l|l|}
\hline Museo Ibarraundi & blica - Ayuntamiento & blica - Ayuntamiento \\
\hline Museo Laboratorium & vada - Otra & vada - Otra \\
\hline Museo de Arte Sacro de Vizcaya & $\begin{array}{l}\text { vada - Instituciones } \\
\text { Religiosas (Obispado de } \\
\text { Bilbao) }\end{array}$ & $\begin{array}{l}\text { vada - Instituciones } \\
\text { Religiosas (Obispado de } \\
\text { Bilbao) }\end{array}$ \\
\hline Museo Marítimo de Asturias & blica - Ayuntamiento & $\begin{array}{l}\text { vada - Persona jurídica } \\
\text { (Fundación) }\end{array}$ \\
\hline Muso Municipal Jerónimo Molina & blica - Ayuntamiento & blica - Ayuntamiento \\
\hline
\end{tabular}

Fuente: Elaboración propia a partir de las respuestas aportadas 